\title{
PROPOSTAS DE ATIVIDADES DE CRIAÇÃO MUSICAL PARA A EDUCAÇÃO INFANTIL NO CONTEXTO MUSICAL DO SÉCULO XX.
}

André Morales Torcato ${ }^{1}$, Patrícia Mertzig Gonçalves de Oliveira ${ }^{2}$, Luciana Carolina Fernandes de Faria $^{2}$

${ }^{1}$ Discente do curso de Música-Licenciatura da Universidade do Oeste Paulista - UNOESTE. ${ }^{2}$ Docente do curso de Música-Licenciatura da Universidade do Oeste Paulista - UNOESTE

\section{RESUMO}

O presente artigo visa compreender e analisar os métodos de Educação Musical que propõe atividades para o desenvolvimento da criação musical, seja por improviso ou composição, de forma a identificar se essas propostas de atividades pedagógicas são adequadas à aplicação na Educação Infantil. Foram selecionadas duas propostas pedagógicas, Brito (2012) e Schafer (2011), que destacam a importância da criação musical no processo de educação e conglobam as sonoridades e formas musicais exploradas pela cultura ocidental durante o século XX. Ao analisá-las, conclui-se que crianças de zero a seis anos podem ser musicalizadas por meio destas atividades de criação.

Palavras-chave: Criação Musical, Educação Infantil, Educação Musical, Ensino Musical no Século $\mathrm{XX}$.

\section{INTRODUÇÃO E OBJETIVOS}

A criação artística musical é uma atividade criadora, um fazer humano fundamental à formação integral do ser humano. Tal concepção de criação artística musical, aliada à compreensão do contexto musical vivenciado no ocidente a partir do século XX e a relevância e aplicabilidade de tal conhecimento junto a Educação Infantil, por meio de atividades, apresenta-se como importante meio para a promoção de uma Educação Musical consciente e efetiva.

Os educadores musicais constantemente se voltam para questões simples, porém fundamentais: O quê ensinar? Como ensinar? Durante seu processo de formação, seja a formação inicial, continuada e a experiência cotidiana, estes educadores estão constantemente se relacionando à prática musical e à execução de instrumentos musicais diversos. Além disso, a cada prática e reflexão são convidados a repensar todo seu conhecimento musical, artístico e cultural e reconstruir suas práticas pedagógicas.

O estudo dos métodos ativos em Educação Musical, mais do que apresentar um repertório de atividades a serem desenvolvidas em sala de aula, possibilita ao professor de música conhecer as bases teóricas e as concepções musical e pedagógica que fundamentam tais métodos. Conhecendo essas concepções e fundamentos o professor é formado de maneira autônoma e é capaz de elaborar suas próprias atividades de educação musical, bem como adaptá-las para sua 
realidade em sala de aula. Oliveira (2009) define método como sendo

[...] a organização sistemática de material cujo princípio é como ensinar música e não ensinar sobre música. E ainda apresenta um posicionamento teórico com fundamentos filosóficos, sociológicos, psicológicos, antropológicos e pedagógicos (OLIVEIRA, 2009, p. 47).

Com o presente artigo, nossa atenção se volta para as formas musicais desenvolvidas no ocidente, no século XX, que apresentam características distintas das formas musicais desenvolvidas nos séculos anteriores. Candé (2001) observa que, anteriormente ao século XX, havia um conjunto de características comuns entre compositores, tanto de mesma época, como de épocas diferentes; a partir do século XX, surge não apenas um conjunto de características, mas diversos, tão distintos do conjunto de características anterior, quanto distintos entre si. “Desde Debussy, assiste-se a uma contestação geral do sistema e das regras acadêmicas: princípio das relações tonais, desenvolvimento temático, formas tradicionais" (CANDÉ, 2001, p.183).

$\mathrm{O}$ sistema tonal, contestado durante o século XX, é baseado em sons organizados a partir de uma estrutura lógica, de maneira que o discurso musical detém-se em algumas poucas possibilidades direcionais. Além disso, cada um destes tons ocupa um espaço no tempo muito bem definido, conforme regras de proporções delineadas pelo fracionamento de sua unidade de medida.

[...] a habilidade de levar o sistema tonal às últimas consequências constituiu-se, por seu lado, no alcance do mais alto patamar de seu domínio e, por outro, no enfraquecimento do próprio sistema, incapaz de superar suas últimas conquistas (FONTERRADA, 2009, p. 80).

Quando verificada a história da cultura ocidental pode-se constatar que desde o final da Idade Média o sistema musical que se desenvolveu foi o tonal. A cada época com seus compositores, intérpretes e estudiosos desta arte, o que se obteve, foi o enriquecimento desse sistema. Em cada período agregação de valores, regras musicais e exploração de seus limites. Contudo, a partir do século XX, nota-se a exploração musical para além dos limites deste sistema, a tal ponto que passam a existir linhas tão distintas do sistema tonal que vigoram como negação ou contestação, o que levou à constituição de novos sistemas musicais.

Aliás, poderia ser de outro modo? Nas outras épocas, podia-se definir uma "linguagem" musical comum aos compositores de uma ou mais gerações. Os mais audaciosos transformavam periodicamente esse instrumento em proveito das gerações seguintes. Desde o início do século $\mathrm{XX}$, ao contrário, existiram simultaneamente técnicas ou até sistemas musicais inconciliáveis, incompatíveis, irredutíveis uns aos outros: sistema tonal "enriquecido", 
politonalidade, dodecafonismo serial, músicas em quarto de tom (ou outras frações de tons), sistema modal ampliado, música eletroacústica, músicas aleatórias ou probalistas, jazz, música funcional ou de grande consumo (sistema tonal empobrecido), etc. (CANDE, 2001, p. 183).

Uma vez que a realidade musical mudou, será que as atividades propostas pelas abordagens metodológicas em educação musical existentes a consideram?

O conhecimento musical é desenvolvido em três modalidades, sendo elas apreciação, execução e criação. A apreciação possibilita um desenvolvimento da capacidade perceptiva auditiva, fundamental à prática musical. A execução, como reprodução, permite a reflexão sobre os sons percebidos, enquanto se refaz o caminho pelo qual a música deixa seu universo intangível e passa ao tangível, quando de fato realiza-se como arte temporal. A atividade de criação musical, seja como improviso ou como composição, faz mais do que repensar, ela busca o novo, o que ainda não foi realizado, exigindo assim um maior domínio do conhecimento e habilidade musical que as modalidades de apreciação e execução.

Para a Educação Infantil, atividades que proporcionem conhecimento oferecem aos alunos noção do que já é real, enquanto atividades que proporcionem execução do conhecimento oferecem o entendimento sobre a realidade, mas finalmente, atividades que proporcionem criação permitem a expansão da realidade.

Vygotsky (2000) defende que criação artística se baseia em algo real, reproduzindo-o por meio de nova forma, produzindo algo efetivamente novo. Gardner (1997) assume que "o criador ou artista é um indivíduo que obteve suficiente habilidade no uso de um meio para ser capaz de comunicar através de criação de um objeto simbólico" (1997, p. 49).

A atividade de criação é efetivamente um fazer humano, visto como uma forma de interpretação do mundo, uma maneira de compreensão das experiências vivenciadas. Para Vygotsky (2008), a criação é matéria de interesse para vários ramos da psicologia, sobretudo os que estudam a emoção e os sentimentos.

Llamamos actividad creadora a toda realización humana creadora de algo nuevo, ya se trate de reflejos de algún objeto del mundo exterior, ya de determinadas construcciones del cerebro o del sentimiento que viven y se manifiestan sólo en el propio ser humano (VIGOTSKY, 2000, p. 7).

Shünemann (2010) considera o contato com a música, um fator beneficente no desenvolvimento e crescimento da criança, inclusive na sua socialização. Já Gardner (1997) aponta em suas pesquisas, o fato de que crianças com baixo QI ou alguma deficiência mental, sobretudo o 
autismo, podem demonstrar um bom desempenho nas práticas musicais.

Considerando os apontamentos de Vygotsky (2000/2008), Gardner (1997) e Shünemann (2010), é relevante estudar e compreender atividades que envolvam a criação musical, seja em forma de composição ou de improvisação. Observa-se uma mudança de realidade no cenário musical como arte, como exploradora de seus próprios limites, questionando a existência de métodos em educação musical apropriados.

Sem dúvida, uma realidade sonora e musical se impõe no decorrer do século XX e se arrasta pelo século XXI: uma realidade musical cada vez mais aberta a sonoridades até então consideradas não-musicais; uma realidade que é percorrida por uma linha bastante tênue que não distingue mais educação musical da composição ou da interpretação; uma realidade na qual a escuta tem papel preponderante, seja na produção, seja na recepção musical; uma realidade da qual não conseguimos nos esquivar e nos faz questionar conceitos, pedagogias, metodologias musicais, forçando-nos a abrir as "janelas" dos ouvidos, dos olhos, das ideias, dos conceitos e perguntar: Que música ensinamos às crianças? Quais são suas ideias de música (SANTOS, 2006, p. 3)?

A partir de uma nova realidade musical e novas possibilidades sonoras, o presente artigo busca compreender como os métodos para Educação Musical que conglobam as sonoridades e formas musicais, exploradas a partir do século XX, propõem o desenvolvimento da criação musical e se tais propostas de atividades pedagógicas são adequadas à aplicação na Educação Infantil.

\section{METODOLOGIA}

Para atingir os objetivos de compreender os métodos de Educação Musical, fundamentados em uma perspectiva contemporânea, e analisar se tais propostas de atividades pedagógicas de criação musical são adequadas à aplicação na Educação Infantil, este artigo tem como metodologia de pesquisa a coleta bibliográfica de dados em Brito (2012) e Schafer (2011) e análise à luz de Fonterrada (2008), Oliveira (2009) e Santos (2006).

\section{RESULTADOS}

Brito (2012) propõe, em seu trabalho, atividades de sonorização de histórias, através das quais as crianças são estimuladas a produzir sons de acordo com um roteiro, ora determinado pelo professor, ora desenvolvido pelas próprias crianças. O professor pode, a princípio, contar uma história e sugerir que as crianças escolham uma maneira de representar o que estão ouvindo, compreendendo todo o ambiente sonoro como: porta se abrindo, pessoa correndo ou algum 
animal conhecido por elas. Em seguida, passando para situações cada vez mais complexas até que se consiga representar elementos abstratos, chegando ao ponto de contar uma história apenas com os recursos sonoros sem articulação de palavras.

Schafer (2011) relata suas experiências em sala de aula, anotando tanto diálogo com seus alunos quanto as atividades propostas. O tempo todo o professor questiona conceitos musicais e instiga os alunos a reconstruírem, conjuntamente, os elementos formadores destes conceitos, experimentando com seus próprios instrumentos musicais. De início, o professor indaga sobre a possibilidade de usar instrumentos musicais a fim de imitar sons produzidos pelo homem como: metralhadora ou risadas; ou ainda sons produzidos pela natureza como: pássaros ou uma queda d'água. Ao ouvir a imitação de pássaros pelos flautistas, o professor faz um traçado aleatório na lousa, com curvas curtas, longas, côncavas e convexas e pede para que os flautistas retomem a imitação considerando esse desenho como uma possível movimentação dos pássaros. Na sequência, o professor propõe outros modelos reais, em que os alunos tentam imitar com seus instrumentos e ao final, ele realiza uma representação gráfica do que foi executado. O professor segue desenhando na lousa, com traços elementares compostos por retas e curvas, pedindo para que os alunos representem com seus instrumentos musicais, sem contudo, sugerir algum contexto concreto.Ao incluir um grupo maior de alunos, a forma de interpretação dos desenhos pode ser convencionada, estabelecendo as principais relações com os parâmetros de som, como grave e agudo; forte e fraco; e rápido e lento.

\section{DISCUSSÃO}

Analisada a proposta da sonorização de histórias, deparamo-nos com um pequeno agrupamento de atividades inter-relacionadas, que podem, efetivamente, ser aplicadas à Educação Infantil. A ideia de se utilizar narração de histórias não é novidade nas práticas pedagógicas em Educação Infantil e a escolha do repertório pode ser adequada pelo próprio professor, observados o contexto sociocultural de seus alunos, bem como sua faixa etária. Os recursos materiais e pedagógicos aplicados também podem ser facilmente adaptados à realidade discente, como por exemplo, o uso de instrumentos confeccionados com sucata, não apenas pelo custo baixo, mas pelas possibilidades de confecção por parte dos alunos, estabelecendo uma relação afetiva com os instrumentos.

As atividades propostas por Brito (2012) podem ser aplicadas de forma gradativa, respeitando o desenvolvimento de cada criança participante, dando maior suporte no início e mais 
liberdade com o tempo. As crianças começam criando soluções sonoras para os problemas propostos pelo professor, como por exemplo, imitar o som de algum animal que aparece na história. Na sequência, têm oportunidade de contar uma história que conheçam, ou mesmo inventar sua própria, criando novas oportunidades para intervenção sonora.

Uma vez explorados os recursos sonoros como apoio para a história, o professor pode sugerir, finalmente, que as crianças tentem narrar uma história, utilizando apenas estes elementos, excluindo totalmente o uso de palavras.

Se compararmos a proposta de Brito (2012) com Schafer (2011), observamos que a segunda demanda maior habilidade de abstração, exigida desde a primeira etapa, contudo, ela se torna mais elementar ao sugerir ideias simples de aplicação dos parâmetros do som. $\mathrm{O}$ trabalho de Schafer (2011) relata suas próprias experiências em sala de aula, e sua atividade proposta se insere em meio a um diálogo com seus próprios alunos, dispostos em uma sala de aula e tendo instrumentos musicais à disposição. De início, o professor discute a definição de música com seus alunos, instigando o grupo a construir o conhecimento sobre ela e as maneiras pelas quais ela possa ser construída. A atividade começa a ganhar forma quando o professor questiona seus alunos sobre a representatividade de um trecho musical executado, sob que aspectos fora desenvolvida, e o que pretende transmitir. O professor não apresenta os conceitos prontos, formados sobre este assunto, mas instiga os alunos a delinear a maneira pela qual a música transmite ideias ou as representa, ou se isso não é realizável.

À medida que o professor desenha, os alunos tentam representar os símbolos musicalmente. As primeiras respostas registradas associam os traços com os parâmetros mais básicos, como agudo e grave. Então o professor questiona sobre a possibilidade dele usar desenhos diferentes, porém de traços similares, de forma que, considerando o resultado da primeira atividade, o resultado desta segunda também fosse diferente, porém similar, embora o significado original dos desenhos fossem, supostamente, bem diferentes. Por exemplo, o primeiro desenho pode representar uma árvore, e o segundo uma montanha, mas seus traços rudimentares podem ser bem parecidos, levando a um resultado sonoro também parecido, conforme a realização dos alunos frente à primeira atividade.

O professor então pede aos alunos que desenhem e tentem executar, ou então que troquem os desenhos para que outro colega o interprete. Em seguida, o professor cria outro desenho mais complexo e abstrato, com traços e curvas sem, contudo, formar alguma figura concreta, alternando mais uma rodada de composição dos alunos. De tempos em tempos, o 
professor interrompe o trabalho dos alunos, questionando-os sobre seus resultados e impressões.

\section{CONCLUSÃO}

As atividades desenvolvidas relativas à sonorização de histórias permitem às crianças um primeiro contato com a criação musical. Por ser baseada em sons explorados intuitivamente, valoriza seu resultado, sem, contudo, se preocupar com quaisquer outras estruturas, remetendo à música desenvolvida no ocidente, durante o século XX. Não há tons definidos, e os efeitos sonoros não se conectam entre si por quaisquer padrões rítmicos. Todos os sons produzidos existem por si só e cumprem uma função independente das demais. Embora a primeira proposta configure uma criação sonoplástica, a segunda conduz ao desenvolvimento de uma obra musical por completo, onde os diversos elementos narrativos da história imaginada são representados musicalmente. Com isso, a criança tem a oportunidade de desenvolver habilidades de abstração e imaginação.

Um desenho, por si mesmo, é uma forma abstrata de representação, embora possa assumir aspectos de fácil compreensão, seu traçado pode remeter a outras ideias, sejam concretas ou abstratas. E este é o principal diferencial entre as duas propostas: na primeira, obtém-se uma representação abstrata sobre uma ideia concreta, e na segunda, uma representação abstrata sobre uma ideia abstrata. O principal conceito da segunda proposta tende a definição da representatividade musical e maneira pela qual se pode diferenciá-la. As atividades culminar-se-ão em propostas de composição, em que o aluno desenvolve uma forma gráfica abstrata e a interpreta musicalmente. Assim como a proposta anterior, aqui também estão descartadas as regras do sistema tonal, de forma a não limitar as possibilidades de representação sonora. 0 resultado obtido das composições podem se assemelhar às composições tonais, mesmo que os mecanismos de sua concepção não estejam claramente presentes.

As duas propostas analisadas resultam em atividades de criação musical, cujos resultados apresentam consonância com o contexto musical vivenciado pelo ocidente durante o século XX. Ambas demonstram ser adequadas para aplicação na Educação Infantil, a primeira para os anos iniciais, e a segunda para os anos subsequentes, e cumprem com objetivo de estimular a criatividade e a abstração de elementos intangíveis.

\section{REFERÊNCIAS}

BRITO, T. A. de. Música na Educação Infantil. 1ª̣ Edição - São Paulo: Peirópolis, 2012.

CANDÉ, R. História Universal da Música: volume 2. 2ª Edição - São Paulo: Martins Fontes, 2001. 
FONTERRADA, M. T. de O. De tramas e fios. Um ensino sobre música e educação. $2^{\underline{a}}$ Edição - São Paulo: Editora UNESP, 2008.

GARDNER, H. As artes e o desenvolvimento humano: um estudo psicológico artístico. 1aㅡ Edição Porto Alegre: Artes Médicas, 1997.

OLIVEIRA, P.L.L.M. G. de. Educação musical e algumas metodologias: um estudo de abordagem teórica. Dissertação de mestrado. Universidade Estadual de Maringá. Programa de Pós-graduação em Educação, 2009.

SANTOS, F. C. dos. A paisagem sonora, a criança e a cidade: exercícios de escuta e de composição para uma ampliação da ideia de música. Tese de Doutorado. Universidade Estadual de Campinas, Instituto de Artes. Programa de Pós-Graduação em Música, 2006.

SCHAFER, R. M. O Ouvido Pensante. 2ª Edição - São Paulo: Ed. Unesp, 2011.

SHÜNEMANN, A. T. Música e histórias infantis: o engajamento da criança de 0 a 4 anos nas aulas de música. Dissertação de Mestrado. Universidade Federal do Rio Grande do Sul. Programa de PósGraduação em Educação, 2010.

VYGOTSKY, L. S. La Imaginación y el Arte em la Infancia (Ensayo Psicológico). 5aㅡ Edição - Madrid: Ediciones Akal, S. A., 2000.

L. S. Piscologia Del Arte. 1ํㅡㄹ Edição - Buenos Aires: Paidós, 2008. 